Original Research Article

\title{
Evaluation of the oral hypoglycemic activity of methanolic extract of Garcinia indica seeds in streptozotocin induced diabetic Albino rats
}

\author{
Padmaja Shetty K.*, Pushpa V. H.
}

Department of Pharmacology, JSS Medical College, Mysore, Karnataka, India

Received: 19 March 2018 Accepted: 25 April 2018

*Correspondence to:

Dr. Padmaja Shetty K.,

Email: padmajaalva@gmail.com

Copyright: (C) the author(s), publisher and licensee Medip Academy. This is an openaccess article distributed under the terms of the Creative Commons Attribution NonCommercial License, which permits unrestricted noncommercial use, distribution, and reproduction in any medium, provided the original work is properly cited.

\begin{abstract}
Background: Diabetes mellitus is a multifactorial metabolic disorder with several microvascular and macrovascular complications. Several plants have been used as dietary adjuvants to conventional drug therapy. Garcinia indica exhibits significant hypolipidemic and hypoglycemic activity. This study was conducted to evaluate the hypoglycemic effects of methanolic extract of seeds of Garcinia indica on blood glucose levels in Streptozotocin induced diabetic albino rats.

Methods: Five groups of wistar albino rats $(n=6)$ weighing $150-200 \mathrm{~g}$ of either sex aged 3-4 months were obtained for the study. After overnight fasting, streptozotocin $(50 \mathrm{mg} / \mathrm{kg}$ ) was administered intraperitoneally to induce diabetes. Five groups are: Group-1: Non diabetic control group, Group-2: diabetic control, Group-3: diabetic standard, Group-4: test group, Group-5: half of test + half of standard. Fasting blood sugar was estimated on 1, 3, 7, 14 and 28th day by capillary blood glucose method. The data obtained were subjected to statistical analysis.
\end{abstract}

Results: In this study, following Streptozotocin administration the blood glucose levels increased in all groups on day 0 . In group 2, blood glucose level gradually increased to $445.6 \pm 1.75 \mathrm{mg} / \mathrm{dl}$ over a period of 4 weeks. Following glibenclamide administration in Group 3 - there was a gradual reduction in blood glucose levels: $269.8 \mathrm{mg} / \mathrm{dl}$ - day 7 to $101.8 \mathrm{mg} / \mathrm{dl}$ - week 4 . Group 4 - persistent and significant $(\mathrm{p}<0.05)$ fall in blood glucose levels reaching upto $107 \mathrm{mg} / \mathrm{dl}$ at the end of 4 weeks. Group $5-330 \mathrm{mg} / \mathrm{dl}$ on day 1 which significantly $(\mathrm{p}<0.05)$ reduced to $101 \mathrm{mg} / \mathrm{dl}$ on day 28 . There was improvement in weight in group 4 and group 5 diabetic rats.

Conclusions: The extract alone and in combination with glibenclamide showed significant hypoglycemic activity in comparison to diabetic control group.

Keywords: Diabetes mellitus, Garcinia indica, Glibenclamide, Streptozotocin

\section{INTRODUCTION}

Diabetes mellitus is a group of metabolic disorders caused by a complex interaction of genetics and environmental factors. This condition is characterised by the development of hyperglycemia due to reduced insulin secretion, decreased glucose utilization and increased glucose production. ${ }^{1}$
The metabolic consequences of prolonged hyperglycemia and dyslipidemia result in microvascular and macrovascular complication including accelerated atherosclerosis, chronic kidney disease, blindness, neuropathy, peripheral vascular disease etc. ${ }^{2}$ The two broad categories of diabetes mellitus are designated type 1 and type 2. Type 1 diabetes mellitus is the result of complete or near-total insulin deficiency. ${ }^{3}$ Type 2 diabetes mellitus is a heterogeneous group of disorders 
characterized by variable degrees of insulin resistance, impaired insulin secretion and increased glucose production and is often triggered by obesity, stress or sedentary lifestyle. ${ }^{4}$ Globally, an estimated 422 million adults were living with diabetes in 2014, compared to 108 million in 1980. The global prevalence (age-standardized) of diabetes has nearly doubled since 1980 , rising from $4.7 \%$ to $8.5 \%$ in the adult population. ${ }^{5}$ India will have the largest number of diabetic population with type 2 diabetes mellitus by $2030 .^{6}$

Type 1 diabetes mellitus is a chronic autoimmune disease associated with selective destruction of insulin-producing pancreatic $\beta$-cells, characterized by presence of immunocompetent and accessory cells in infiltrated pancreatic islets usually leading to absolute insulin deficiency. Type 2 diabetes mellitus is characterised by impaired insulin secretion through a dysfunction of the pancreatic $\beta$-cell and impaired insulin action due to insulin resistance. Insulin resistance and hyperinsulinemia eventually lead to impaired glucose tolerance. This is is often associated with a family history of diabetes, older age, obesity and sedentary lifestyle. ${ }^{7}$ Patients with diabetes experience significant morbidity and mortality from microvascular (retinopathy, neuropathy, nephropathy) and macrovascular complications (heart attack, stroke and peripheral vascular disease).$^{8}$

Several conventional and newer treatment regimes are available for management of type 2 diabetes such as sulfonylureas like tolbutamide, thiazolidinediones like pioglitazone, $\alpha$ glucosidase inhibitors, GLP 1 agonists, DPP - IV inhibitors, amylin agonist, PPAR $\gamma$ agonists etc. These agents have several adverse effects such as hypoglycemia, lactic acidosis, metallic taste, abdominal pain, anorexia, nausea, dyspepsia to mention a few. ${ }^{9}$

Several plants have been used as dietary adjuvants to conventional drug therapy. Several plant species such as Opuntia streptacantha Lem, Trigonella foenum graecum L, Momordica charantia L, Ficus bengalensis L, L., Gymnema sylvestre R., Allium sativum, Citrullus colocynthis, myrrh, black seeds, helteet, fenugreek, aloe and Artemisia have been identified with hypoglycaemic activity. Phytochemicals like glycosides, alkaloids, terpenoids and flavonoids have been implicated as having antidiabetic effects. ${ }^{10}$

Garcinia indica also called Malabar tamarind belongs to Clusiaceae (earlier Guttiferae) family of Garcinia. The tree is distributed throughout Africa, Asia, Polynesia and is commonly found in western ghats, north eastern parts of India. The parts of the plant such as roots, leaves, fruit rind have been traditionally used in several herbal preparations. ${ }^{11}$ Several phytoconstituents like xanthones, biflavonoids, benzophenones, hydroxycitric acid, fatty acids, glycerides, anthocyanins, garcinol, camboginol, etc which exhibit significant hypolipidemic and hypoglycemic activity have been isolated from several parts of the tree. ${ }^{12}$ However through this study we have evaluated the hypoglycemic effects of methanolic extract of seeds of Garcinia indica on blood glucose levels in Streptozotocin induced diabetic albino rats.

\section{METHODS}

There were five groups of Wistar albino rats $(n=6)$ of either sex aged 3-4 months in each group with average weight 150-200g were obtained for the study from the Central Animal House Facility, Department of Pharmacology, JSS Medical College, Mysore and housed in clean polypropylene cages with $12 \mathrm{~h}$ light /dark cycle at $25 \pm 2^{\circ} \mathrm{C}$ and $65 \pm 5 \%$ humidity. They had access to food (standard pellet diet, Hindustan Lever Ltd) and water. All experiments were carried out between 11 AM and 3 PM. The ethical clearance was obtained from the Institutional Animals Ethical Committee and all the experiments have been carried according to CPCSEA guidelines (JSSMC/PR/IAEC/08/2012-2013).

After overnight fasting, freshly prepared streptozotocin $(50 \mathrm{mg} / \mathrm{kg})$ in citrate buffer was administered intraperitoneally to induce diabetes mellitus. The rats meeting the inclusion and exclusion criteria with fasting blood glucose levels more than $200 \mathrm{mg} / \mathrm{dl}$ were selected for the study.

Seeds of Garcinia indica was obtained in sufficient quantity from the western ghats, Kundapur, Karnataka and it was shade dried. It was powdered and methanolic extract of seeds was prepared using soxhlet apparatus.

After administration of streptozotocin, the respective drugs were administered to the groups for a duration of 28 days orally, once daily. Group-1: Non diabetic control group (normal saline:0.5ml $/ \mathrm{kg}$ ), Group - 2: diabetic control (normal saline: $0.5 \mathrm{ml} / \mathrm{kg}$ ), Group- 3: diabetic standard (glibenclamide- $0.5 \mathrm{mg} / \mathrm{kg}$ ), Group - 4: test group (methanolic extract of Garcinia indica seeds- 300mg $/ \mathrm{kg}$ ), Group - 5: half of test (methanolic extract of Garcinia indica seeds- $150 \mathrm{mg} / \mathrm{kg})+$ half of standard (glibenclamide- $0.25 \mathrm{mg} / \mathrm{kg}$ ).

General clinical observations, morbidity and mortality were made for any side effects at least once a day throughout the study period of 28days. Weight of the rats were measured on days 1, 14, 28 and fasting blood sugar was estimated on 1, 3, 7, 14 and 28th day by capillary blood glucose method.

Statistical analysis included mean and standard deviation calculated for each group. One way ANOVA was used for multiple group comparison followed by post hoc Tukey's test for statistical significance between groups. $\mathrm{P}$ value less than 0.05 was considered as statistically significant.

\section{RESULTS}

In this study, the mean blood glucose levels before the induction of diabetes in all five groups varied from 80- 
$120 \mathrm{mg} / \mathrm{dl}$. Following Streptozotocin administration the blood glucose levels increased in all groups on day 0 (Table 1). In group 2, blood glucose level gradually increased to $445.6 \pm 1.75 \mathrm{mg} / \mathrm{dl}$ over a period of 4 weeks.
Following Glibenclamide administration in Group 3, there was a gradual reduction in blood glucose levels: $269.8 \mathrm{mg} / \mathrm{dl}$ - day 7 to $101.8 \mathrm{mg} / \mathrm{dl}$ - at the end of 4 weeks (Table 1).

Table 1: Effect of methanolic extract Garcinia indica seeds on blood glucose levels in different groups on respective days.

\begin{tabular}{|lll|llll|}
\hline Groups & $\begin{array}{l}\text { Day 0 } \\
(\mathbf{m g} / \mathbf{d l})\end{array}$ & $\begin{array}{l}\text { Day 1 } \\
(\mathbf{m g} / \mathbf{d l})\end{array}$ & $\begin{array}{l}\text { Day 7 } \\
(\mathbf{m g} / \mathbf{d l})\end{array}$ & $\begin{array}{l}\text { Day 14 } \\
(\mathbf{m g} / \mathbf{d l})\end{array}$ & $\begin{array}{l}\text { Day 21 } \\
(\mathbf{m g} / \mathbf{d l})\end{array}$ & $\begin{array}{l}\text { Day 28 } \\
(\mathbf{m g} / \mathbf{d l})\end{array}$ \\
\hline Group 1 & $105 \pm 4.47$ & $103.6 \pm 4.2$ & $103.8 \pm 3.18$ & $103 \pm 5.05$ & $106.6 \pm 4.08$ & $104 \pm 3.74$ \\
\hline Group 2 & $340.3 \pm 1.86$ & $352.3 \pm 3.90$ & $372.8 \pm 8.68$ & $410 \pm 3.57$ & $425 \pm 2.96$ & $445.6 \pm 1.75$ \\
\hline Group 3 & $350 \pm 2.44$ & $339.1 \pm 2.40$ & $269.8 \pm 3.25$ & $161.3 \pm 2.94$ & $140.5 \pm 3.67$ & $101.8 \pm 3.65$ \\
\hline Group 4 & $347.1 \pm 1.83$ & $344 \pm 2.0$ & $166.5 \pm 2.50$ & $151.3 \pm 5.64$ & $128.3 \pm 3.50$ & $107 \pm 3.89$ \\
\hline Group 5 & $339 \pm 2.09$ & $330 \pm 4.60$ & $158.5 \pm 2.66$ & $140.5 \pm 3.93$ & $117 \pm 2.0$ & $101 \pm 2.36$ \\
\hline
\end{tabular}

Data are expressed as mean \pm SD

D0: Before administering the drug

D 1, D 7, D 14, D 21, D 28: $1^{\text {st }}, 7^{\text {th }}, 14^{\text {th }}, 21^{\text {st }}$ and $28^{\text {th }}$ days of administration of drugs respectively.

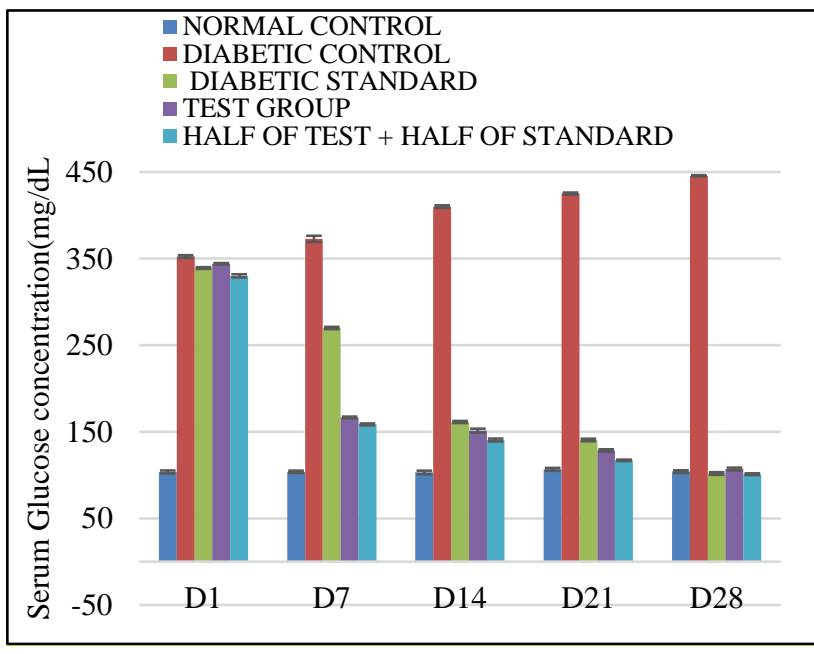

Figure 1: Effect of methanolic extract of Garcinia indica seeds on blood glucose level in STZ-induced diabetics rats.

Each value is expressed as Mean \pm S.E.M. $(n=6)$. Across Time Interval D1 to D 28, Groups have shown significant difference with $\mathrm{p}<0.001$. Data analysis was performed by one-way ANOVA followed by Tukey's post-hoc test.

Statistically significant reduction in blood glucose levels $(\mathrm{p}<0.05)$ in Group 3 was seen on day 1 , day 7, day 14, day 21 and day 28 in comparison to diabetic control group. There was persistent fall in blood glucose levels reaching upto $107 \mathrm{mg} / \mathrm{dl}$ at the end of 4 weeks (Table 1). The test drug (Methanolic extract of Garcinia indica seeds) showed maximum fall in blood glucose levels on day 7 and persistent fall upto day 28 in comparison to both diabetic control and standard groups. Statistical analysis showed significant fall in blood glucose levels on day 1, 7, 14, 21 $(\mathrm{p}<0.05)$ in comparison to both diabetic control and standard groups (Figure 1).
The blood glucose levels in group 5 of $330 \mathrm{mg} / \mathrm{dl}$ on day 1 significantly reduced to $158.5 \mathrm{mg} / \mathrm{dl}$ on day $7,140.5 \mathrm{mg} / \mathrm{dl}$ on day $14,117 \mathrm{mg} / \mathrm{dl}$ on day 21 and finally $101 \mathrm{mg} / \mathrm{dl}$ on day 28. Statistical analysis showed significant $(\mathrm{p}<0.05)$ reduction in blood glucose levels in test + standard group on day 1 , day 7 , day 14 , day 21 and day 28 respectively (Figure 1).

Percentage reduction of blood glucose was significant in both test groups and standard group (Table 2). Group 2 showed $23.7 \%$ increase in blood glucose levels at the end of 4 weeks. In Group 3, percentage reduction in blood glucose levels in comparison to diabetic control group was $3.75 \%$ on day 1 and $77.15 \%$ on day 28 . The percentage reduction in blood glucose in Group 4 in comparison to diabetic control was $2.4 \%$ on day 1 followed by $55.3 \%$ on day $7,63.09 \%$ on day 14 and finally $76 \%$ on day 28 . The percentage fall in blood glucose levels in Group 5 compared to standard group was $38.3 \%$ on day 7 .

Table 2: Percentage reduction in blood glucose levels in standard and test groups in comparison to diabetic control group.

\begin{tabular}{|lllllll|}
\hline Groups & Day & & & & & \\
& $\mathbf{0 \%}$ & $\mathbf{1 \%}$ & $\mathbf{7 \%}$ & $\mathbf{1 4 \%}$ & $\mathbf{2 1 \%}$ & $\mathbf{2 8 \%}$ \\
\hline Group 3 & NA & 3.75 & 27.60 & 60.70 & 67.0 & 77.15 \\
\hline Group 4 & NA & 2.40 & 55.30 & 63.09 & 69.80 & 76.0 \\
\hline Group 5 & NA & 6.30 & 57.50 & 65.70 & 72.50 & 77.33 \\
\hline
\end{tabular}

There was no significant change in body weight in group 1 (Control) throughout the study but group 3 (diabetic control) showed $15 \%$ of body weight changes from day 1 to day 28 while in group 4 (test group) initial reduction in body weight was followed by an increase by $\sim 5 \%$ on day 28 and in group 5 (test + standard) increase in body weight was $\sim 2 \%$ (Figure 2 ). 


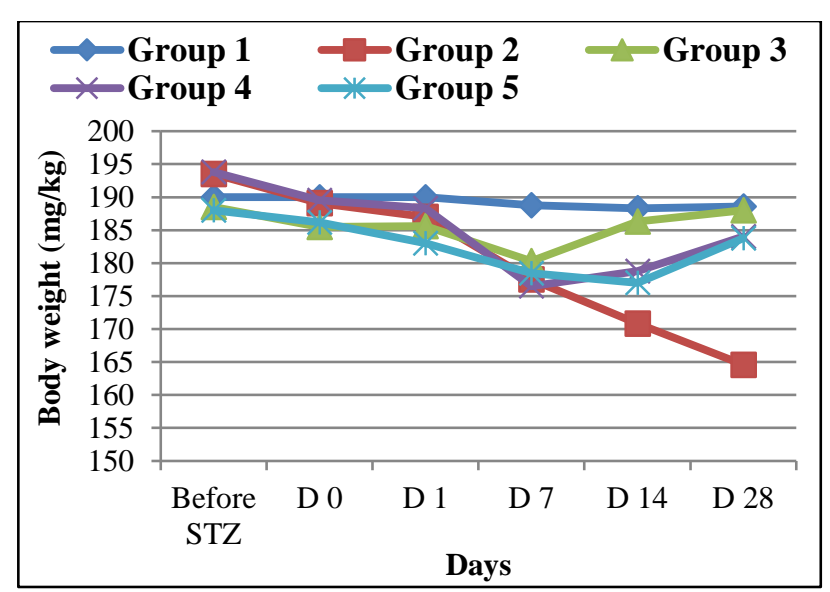

Body weight of the rats are expressed in Mean \pm SD

\section{Figure 2: Body weight of rats in different groups on different days.}

\section{DISCUSSION}

Diabetes mellitus is a major disease characterized by derangement in carbohydrate, fat and protein metabolism, affecting nearly $10 \%$ of the population. Studies have shown that conventional antidiabetic agents such as sulfonylureas, biguanides, thiazolidinedione (TZD), meglitinide, sodium-glucose cotransporter (SGLT2) inhibitors, dipeptidyl peptidase 4 (DPP-4) inhibitors and $\alpha$ glucosidase inhibitors are associated with various adverse effects such as hypoglycaemia, weight gain, comorbidities, nausea, diarrhoea, bloating etc and they do not fulfil the criteria of an ideal antidiabetic agent. ${ }^{13}$ Hence there is need for newer drugs and newer targets for treatment of diabetes. Many Indian medicinal plants are reported to be useful in diabetes.

The study showed that the Group 3 showed a consistent reduction in blood glucose levels from $339.1 \mathrm{mg} / \mathrm{dl}$ on day 1 to $101.8 \mathrm{mg} / \mathrm{dl}$ on day 28 thus showing that glibenclamide could attain good glycemic control in the respective group.

The group 4 and group 5 showed maximum immediate reduction in blood glucose level on day 7 to $166.5 \mathrm{mg} / \mathrm{dl}$ and $158.5 \mathrm{mg} / \mathrm{dl}$ from an initial reading of day 1 . This was followed by consistent reduction in blood glucose levels to $107 \mathrm{mg} / \mathrm{dl}$ and $101 \mathrm{mg} / \mathrm{dl}$ at the end of fourth week.

This observation shows that both the test groups attained significant glycemic control in comparison to both nondiabetic and diabetic control group. The combination of half the dose extract $(150 \mathrm{mg} / \mathrm{kg})$ and standard drug $(0.25 \mathrm{mg} / \mathrm{kg})$ produced reduction in blood glucose levels in comparison to standard group.

The rapid fall in blood glucose levels within a few days of extract administration can be contributed to peripheral mechanism of hypoglycemia. Studies have attributed this effect to inhibitory effect of alpha glucosidase enzyme by saponins, alkaloids, glycosides, tannins and flavonoids which cause decreased glucose transport through intestinal epithelium thus reducing postprandial hyperglycemia. ${ }^{14}$

As a consequence of induction of diabetes in the rats by Streptozotocin there was significant reduction in body weight of rats. The test drugs increased the body weight of rats at the end of 4 weeks of study. Similar change was also observed in the test + standard group and standard group. Weight loss in diabetes is generally due to continuous excretion of glucose from the body. From earlier studies, it was elucidated that body weight of type 2 diabetic rats was found to be less during the course of development as compared to normal animals. Continuous loss of glucose from the body is responsible for weight loss in diabetes. The slow gain in body weight of the treated diabetic animals indicates the efficacy of G. indica in controlling the excessive glucose excretion which in turn maintains the blood glucose level of type 2 diabetic rats. ${ }^{15,16}$

The major phytoconstituents present in Garcinia indica are biflavonoids (kolaflavonones, hydroxybiflavonols), anthocyanins, fatty acids, hydroxycitric acid, garcinol, prenylated benzophenones, xanthones, saponins, tannins, alkaloids, polyphenols and cardiac glycosides. ${ }^{17}$

Aqueous seed extract of Garcinia kola showed significant hypoglycaemic and hypolipidemic effects due to abundant biflavonoids which contribute to its antidiabetic activity by suppressing the glucose levels, reduce plasma cholesterol and triglycerides significantly and increase hepatic glucokinase activity probably by enhancing insulin release from pancreatic islets. ${ }^{18}$

In another study it was shown that hydroxycitric acid found abundantly in this tree have potential effect in stimulating beta cells of islets of Langerhans, regulatory effect on fatty acid synthesis, lipogenesis, appetite and weight loss. ${ }^{19}$

Garcinia indica also contains vitamin $\mathrm{B}_{1}, \mathrm{~B}_{2}, \mathrm{E}$ and vitamin $\mathrm{C}$ which are essential for diabetes prevention, improve insulin sensitivity, glycemic control and prevent protein glycation. Kolaviron, a Garcinia seed extract when administered intraperitoneally has shown antidiabetic and hypolipidemic effects in healthy and alloxan induced rats. ${ }^{20}$

In hyperglycemia, auto-oxidation of glucose increases the formation of free radicals beyond the capacity of defense system to neutralize it and cause oxidative stress. Flavonoids, HCA, garcinol, polyphenols, anghocyanin pigment, ascorbic acid etc found in the plant have antiinflammatory, anti-carcinogenic, antiviral and antioxidant properties. $^{21,22}$

The hydroxycitric acid an important organic acid present in the plant exhibits strong antioxidant activity and prevents the depletion of GSH under stress conditions. Anti-oxidant potential of garcinol present in G. indica may also be responsible for GSH restoration in type 2 diabetic 
rats. It limits the availability of acetyl-CoA required for fatty acid synthesis and promotes glycogenesis, $\beta$ oxidation, etc. These metabolic pathways initiate the uptake of glucose by the muscle and thereby combat insulin resistance of type 2 diabetes ${ }^{23,24}$

It can be elucidated from this study that the extract of Garcinia indica alone produced significant reduction in blood glucose levels in comparison to diabetic control group. While combination of half the dose of extract and half the dose of Glibenclamide produced significant reduction in blood glucose levels in comparison to both diabetic control and standard group. However further studies are required to isolate the phytoconstituents and determine its exact mechanism of action and further subject it to human studies.

\section{CONCLUSION}

This study has shown that the extract alone and in combination with glibenclamide showed significant hypoglycemic activity in comparison to diabetic control group. This indicates that the Garcinia indica can be used as adjuvant therapy along with conventional antidiabetic drugs. The flavonoids (Garcinol, fisetin), hydroxycitric acid, saponins are the important phytoconstituents which have been attributed to the hypoglycemic activity of this plant.

Funding: No funding sources Conflict of interest: None declared

Ethical approval: The study was approved by the Institutional Animals Ethics Committee (JSSMC/PR/IAEC/08/2012-2013)

\section{REFERENCES}

1. Powers AC. Diabetes mellitus. Longo, Fauci, Kasper, Hauser, Jameson, Loscalzo. Harrison's principles of internal medicine. Mc Graw Hill. New York; 2012:2152-2180.

2. Davis SN. Insulin, oral hypoglycemic agents and pharmacology of endocrine pancreas. Laurence Brunton, Bruce Chabner, Bjorn Knollman. Goodman and Gillman's Pharmacological basis of Therapeutics. Mc Graw Hill New York; 2012:1237-1273.

3. Atkinson MA, Eisenbarth GS, Michels AW. Type 1 diabetes. Lancet. 2014;383(9911):69-82.

4. Olokoba AB, Obateru OA, Olokoba LB. Type 2 Diabetes Mellitus: A Review of Current Trends. Oman Medical Journal. 2012;27(4):269-73.

5. World Health organisation. Global report on diabetes. France: WHO Press; 2016. Available at: http://apps.who.int/iris/bitstream/10665/204871/1/97 89241565257_eng.pdf.

6. Kaveeshwar SA, Cornwall J. The current state of diabetes mellitus in India. The Austra Med J. 2014;7(1):45-8.
7. Baynes HW. Classification, Pathophysiology, Diagnosis and Management of Diabetes Mellitus. Journal of diabetes and metabolism. 2015;6:541.

8. Ramachandran A, Das AK, Joshi SR, Yajnik CS, Shah S, Kumar PKM. Current status of diabetes in India and need for novel therapeutic agents. Supplement to Japi. June 2010;58:7-9.

9. Chaudhury A, Duvoor C, Dendi R, Sena V, Kraleti S, Chada A, et al. Clinical review of antidiabetic drugs: Implications for type 2 diabetes mellitus management. Frontiers in endocrinology. 2017 Jan 24;8:6.

10. Stella J, Krishnamurthy P, Mohamed AJ. Hypoglycemic effect of Vitex Agnus Castus in Streptozotocin induced diabetic rats. Asian J of Biochem and Pharmace Res. 2011;2(1):2231-560.

11. Kadam MP, Yadav KN, Patel AN, Navsare VS, Bhilwade SK, Patil MJ. Phytopharmacopoeial specifications of Garcinia indica fruit rinds. Pharmacognosy Journal. 2012 Sep 1;4(31):23-8.

12. Lakshmi C, Kumar KA, Dennis TJ, Kumar TSSPNSS. Antibacterial Activity of Polyphenols of Garcinia Indica. Ind J of Pharmac Sci. 2011;73(4):470-3.

13. Singh A, Dwivedi S. Study of adverse drug reactions in patients with diabetes attending a tertiary care hospital in New Delhi, India. The Ind J of Med Res. 2017;145(2):247-9.

14. Elya B, Basah K, Mun'im A, Yuliastuti W, Bangun A, Septiana EK. Screening of $\alpha$-Glucosidase Inhibitory Activity from Some Plants of Apocynaceae, Clusiaceae, Euphorbiaceae, and Rubiaceae. BioMed Research International. 2011 Dec 7;2012:1-6.

15. Kirana H, Srinivasan B. Aqueous Extract of Garcinia Indica Choisy Restores Glutathione in Type 2 Diabetic Rats. Journal of Young Pharmacists: JYP. 2010;2(3):265-8.

16. Praveen S, Sandhya M, Peeyush A, Sandeep M. Oxidative stress in metabolic syndrome. Indian Journal of Clinical Biochemistry. 2005;20(1):145-9.

17. Ramachandran HD. Plant Profile, Phytochemistry and Pharmacology of Garcinia indica: A Review. Int. J. Pharm. Sci. Rev. Res., July - August 2014;27(2):37681.

18. Kingsley O, Erifeta O, Geogina, Esora US, Sunday JJ, Kazeem AO. Evaluation of hypoglycaemic and antioxidant properties of aqueous extracts of Garcinia Kola seeds in wistar rats. Curr Res J Biol Sci. 2011;3(4):326-9.

19. Jagtap P, Bhise K, Prakya V. A Phytopharmacological Review on Garcinia indica. Inte $\mathbf{J}$ of Her Medic. 2015;3(4):02-7.

20. Adarmoye OA, Adeyemi O. Hypoglycemic and hypolipidemic effects of fractions from kolaviron, a biflavonoid complex from Garcinia kola in streptozotocin induced diabetes mellitus rats. J Pharm Pharmacol. 2006;58(1):121-8.

21. Tharachand SI, Avadhani M. Medicinal properties of malabar tamarind [Garcinia cambogia (Gaertn) DESR]. Int J Pharm Sci Rev Res. 2013;19(2):101-7.

22. Halliwell B. Food-Derived Antioxidants: how to evaluate their importance in food and in vivo. Enrique 
Cadenas Lester Packer. Handbook of Antioxidants. Second Edition. New York, Marcel Dekker, Inc.:2002;18-62.

23. Yamaguchi F, Ariga T, Yoshimura Y, Nakazawa H. Anti-oxidant and anti-glycation activity of garcinol from Garcinia indica fruit rind. J Agric Food Chem. 2000;48:180-5.

24. Yamaguchi F, Saito M, Ariga T, Yoshimura Y, Nakazawa H. Free radical scavenging activity of garcinol from Garcinia indica fruit rind. J Agric Food Chem. 2000;48:2320-5.

Cite this article as: Shetty PK, Pushpa VH. Evaluation of the oral hypoglycemic activity of methanolic extract of Garcinia indica seeds in streptozotocin induced diabetic Albino rats. Int J Basic Clin Pharmacol 2018;7:1147-52. 